\title{
Reading Comprehension and Metacognitive Strategies in First Year Engineering University Students in Pakistan
}

\author{
Mansoor Ahmed Channa ${ }^{1}$, Abdul Malik Abassi ${ }^{2}$, Stephen John ${ }^{3}$, Jam Khan Mohammad ${ }^{4}$, Masood A. Memon ${ }^{5}$ \& \\ Zaimuariffudin Shukri Nordin ${ }^{6}$ \\ ${ }^{1}$ Quaid-e-Awam University of Engineering, Science, and Technology, Nawabshah, Pakistan \\ ${ }^{2}$ Sindh Madressatul Islam University, Karachi, Pakistan \\ ${ }^{3}$ Department of Education, Sindh Madressatul Islam University, Karachi, Pakistan \\ ${ }^{4}$ Mehran University of Engineering, and Technology, Jamshoro, Pakistan \\ ${ }^{5}$ Department of English, Cadet College Petaro, Hyderabad, Sindh, Pakistan \\ ${ }^{6}$ University Malaysia Sarawak, Malaysia \\ Correspondence: Mansoor Ahmed Channa, Quaid-e-Awam University of Engineering, Science, and Technology, \\ Nawabshah, Pakistan. E-mail: mansoor.english@yahoo.com
}

Received: June 7, 2018 Accepted: July 4, 2018 Online Published: July 28, 2018

doi:10.5539/ijel.v8n6p78 URL: https://doi.org/10.5539/ijel.v8n6p78

\begin{abstract}
The paper investigates the use of metacognitive strategies by first year engineering students at the time of classroom practice on reading text. The study was conducted in four engineering departments of a university in Pakistan. Data was collected through focus group interviews of first year engineering students. The researchers developed interview questions which were validated by two experts at university Malaysia Sarawak. Students were divided into 8 groups and each group had 5 informants. The data was recorded in audio-tape and organized gathered data through NVivo version 8 for interpretation of the results. The most important themes were generated through data analysis including thinking through images of the texts, selecting the main ideas, selecting the topic sentences, scanning of the texts, summarizing of the texts, and Questioning. The study contributed theoretically by giving the most promising results which showed that more than half of these groups used metacognitive strategies in classroom reading practice while less than half of groups did not use strategies and remained poor in reading comprehension. This study proposed to develop reading comprehension courses and syllabus based on reading strategies for engineering students.
\end{abstract}

Keywords: metacognition, strategies, reading comprehension

\section{Introduction}

Metacognition is defined as the knowledge and the regulation of students' learning processes (Flavell, 1979). Metacognitive knowledge denotes about the present knowledge of students based on their own cognitive processes. However, metacognitive regulation indicates about the strategies used to supervise their own learning (Flavell, 1979). According to Grotzer and Mittlefehldt (2012), metacognitive knowledge and metacognitive regulation are known as the most essential components used in the activities to study in reading comprehension and problem solving. Chi et al. (1989) found the benefits of metacognition for learning and informed that students, who used metacognitive strategies involving them into self-explanations and in self-monitoring activities, remained better problem solvers as compared to those who did not involve them into such activities. Further, Zimmerman and Schunk (2011) identified metacognition as an important element of self-regulated learning which mostly has been investigated in experimental settings with controlled variables and environments. Flavell (1979) divided metacognitive knowledge into three variables: knowledge of person, task, and strategy. The benefits of metacognitive activities for learning have been observed. For instance, Chi et al. (1989) found that students who engaged in self-explanations, engaged in more self-monitoring activities, and tended to be better problem solvers. White and Frederiksen (1998) found that low achieving students showed learning gains when engaged in metacognitive reflection. Metacognition has also been identified as a critical component of self-regulated learning (Butler et al., 2011). However, very little is known about how students use metacognitive strategies in engineering. 
Many researchers have asserted the value of English in engineering education (Pritchard \& Nasr, 2004; Joesba \& Ardeo, 2005; Venkatraman \& Premak, 2007). Pritchard and Nasr (2004) pointed out that English is the major international language of science enabling students to gain professional knowledge through reading texts. Some authors also stressed that engineering students should be equipped with specific skills, which will become valuable resources in their career (Joesba \& Ardeo, 2005). For engineering students, reading comprehension ability is important in academic settings and their future career to absorb fundamental knowledge in textbooks and deepen professional knowledge in their workplace. It is essential for engineering students to read in fluently. Conversely, there are still a considerable number of engineering students who need help in reading in Pakistan. A number of researchers have recognized engineering students' reading difficulty to vocabulary knowledge and recommended lexical education (Alderson, 2000; Mudray, 2006; Shiotsu \& Weir, 2007; Ward, 2009). Liao and Chen (2012) suggested that if engineering university students want to equip themselves in their career development, suitable Science and technology materials need to be provided in the courses for reading practices. In other words, acquiring reading skill for technology is required in their workplaces in the future. It was demonstrated that increasing learners' awareness of reading skills could facilitate students' reading comprehension of science and technology texts (Liao \& Chen, 2012). However, Keene and Zimmerman (1997) reported that in metacognitive strategies, knowledgeable readers make a planning when they read in order to be aware of their thinking and their comprehending process by selecting strategies (afore reading, in the course of reading, and after reading) text. Similarly, readers can recollect their prior knowledge based on their past practices in order to build associations with reading texts to access easily. Alderson (2000) found that knowledgeable readers attempt to cognize the main part of a reading text by evaluating its importance consistently through three levels (word, sentence, and paragraph levels) in reading comprehension.

\section{Research Background}

Metacognitive strategies can be accomplished using either single strategy or multiple strategies to enable students to acquire their needs in comprehension (Pressley et al., 1998). James (2010) investigated metacognition and found metacognitive strategies as modeled showing the significant improvement in performance of teachers. Song (1998) investigated metacognitive strategies in the context of Korean EFL learners. The findings of the study revealed the effectiveness of strategy use in terms of developing reading comprehension. Therefore, it is important to help the learning of hard engineering concepts and theories which students need to regulate their own learning processes while engaging in their undergraduate education (Streveler et al., 2008). In results, metacognition has been identified to support in the regulation of conceptual learning of engineering (Case et al., 2001). Similarly, metacognitive awareness refers about the effective state of a person involving motivational state, attitudinal state and ability state in order to evaluate certain activities (Brown, 1987). However, the experiences of metacognition take in the knowledge of both processes that include effective process and cognitive process of a person leading towards monitoring the mind process of a person. Different studies provided evidences about the use of metacognition as Fleming and Walls' (1998) study reported metacognition used in language learning. Davidson and Sternberg's (1998) investigation indicated metacognition used in the field of general problem solving in reading comprehension and in critical reading. The study of Antonietti, Ignazi and Pereco (2000) informed about the metacognition in the field of psychology. Additionally, Metacognition as discussed by White (1995) and Oxford (1990) can be the fundamental instruments for the easy success of a person in learning across the curriculum. However, there are increasing evidences that students are graduating from undergraduate institutions while still holding on to robust misconceptions in fundamental areas such as physics, electricity, statics, materials and thermodynamics (Steif et al., 2010; Streveler et al., 2008). To facilitate the learning of difficult engineering concepts, it is important that different skill sets should be identified that students need to regulate their own learning processes while engaging in their first year engineering education. One such skill set that has been identified to aid in the regulation of learning, and in particular conceptual learning, is metacognition (Case et al., 2001).This research supports the need to investigate ways to develop skills and tools that allow students to identify and repair their own misconceptions more adequately. Metacognition has been identified as one such area critical to the development of conceptual knowledge and addressing misconceptions (King \& Kitchener, 2004). In Pakistan, higher education is persistently being reformed from primary to graduate levels. Similarly, the first year engineering students need more help to improve their reading comprehension using different strategies. Metacognition is used to apply engineering students' thinking about and regulating their cognition for developing reading approaches, evaluating, and controlling their learning in an effective manner (Young \& Fry, 2008). 


\section{The Metacognition in Reading}

Metacognition relates to thinking to control over the cognitive processes of students engage in learning how to read and comprehend the text. The strategies involve in metacognition are planning that means how to approach a reading text in terms of proper meaning, monitoring reading comprehension, and evaluating the progress of reading text. Cohen (1998) asserted that metacognitive strategies partially played a part as the operational strategies to boost up students' reading ability. Similarly, Hammadou (1991) stated that students want to upgrade their reading comprehension ability by means of incorporating their former awareness, reading ability, and metacognitive strategies through comprehension of words and sentences in a text to be capable to read efficiently and perceptively. Salataci and Akyel (2002) proposed that metacognitive strategies consist of thinking around what students ensure when they have to read, to check the result of problem solving methods, to plan how to practice with effective strategies, to control the value of an action plan, to test, to revise, and to evaluate strategies. Cohen (1998) further, asserted that metacognitive strategies in reading comprehension help students to make planning before they read, to control monitoring in the reading process, and to make evaluation in terms of their reading and comprehending in the end of the text. This study was conducted to determine which practices using metacognition strategies were to be the most effective tools for engineering students in developing their reading proficiency and comprehension needs. A number of studies (Channa, Nordin, Siming, Chandio \& Koondher, 2015; Channa \& Nordin, 2015; Channa \& Nordin, 2014; Tarricone, 2011; Huff \& Nietfeld, 2009; Mevarech \& Amrany, 2008; Boulware-Gooden, Carreker, Thornhill \& Joshi, 2007; Wei, 2005; Flavell, 2004; Zelazo, 2004; Kramarski \& Mevarech, 2003; Maki \& McGuire, 2002; Schwartz \& Perfect, 2002; Koutselini \& Theofilides, 2001; Demetriou, 2000) suggested that the metacognition field can either be used in teaching or in learning to develop students' awareness of cognition and regulation of cognition in order to raise metacognitive efficiency for comprehension purposes. Similarly, Palincsar and Brown (1984) used meta-strategic in reading through reciprocal teaching method among middle standard students for at least 12 week training program. The findings revealed that metacognitive strategies including self-questioning, summarizing, making predictions, and debugging were considered to be significant. They suggested teachers to use the reciprocal teaching method for developing reading comprehension proficiency.

Moreover, Koch (2001) also taught metacognitive self-assessment strategy in reading comprehension of physics texts to 30 students of pre-university level. Findings of the study revealed that the experimental group beat the control group in reading the texts of physics subject and comprehension. Likewise, Kramarski and Mevarech (2003) examined the effects of metacognitive knowledge and mathematical reasoning by using different teaching techniques on 384 students. The findings revealed that the students using metacognitive strategies performed better with that of those who did not use strategies in reading and learning mathematical and reasoning texts. Similarly, Mevarech and Amrany (2008) arranged training in the field of metacognition and selected 31 secondary school students to use the metacognitive strategies. The researcher divided these 31 students into two groups including the experimental group and the control group. The experimental group was completely guided and supported; whereas control group was not provided any help or guidance about metacognition. The results indicated that the experimental group performed better than the control group. Thus, the study suggested teaching and learning metacognitive strategies for successful comprehension. Recently, Shah, Yusof, Lip, Mahmood, Hamid and Hashim (2010) investigated the use of strategies through survey by comparing strategies in Malaysia. The results of the study indicated that differences were found among average and good readers. Sinthopruangchai (2011) investigated and assessed metacognition and use of reading strategies of students studying Bangkok Christian College, Thailand. Ballou (2012) conducted research on using explicit strategy instruction to improve reading comprehension. Students were analyzed through pre and post-assessment to determine the effectiveness and implications of explicit strategy instruction. Franco-Castillo (2013) investigated strategies through reading and comprehension of science text. This study focused on students' interaction through dialogue journals with their teachers in the class. Data was collected by using different measures. Findings of this study revealed most promising results in terms of comprehension of engineering text.

\section{Research Method}

In this study, qualitative research instrument was used to find the perceptions of first year engineering students. The instrument included focus group interviews from students of four engineering departments in Pakistan. A total of forty students from a university in Pakistan volunteered to participate in the study. The main objective of this qualitative research was to identify strategies and provide a list to the students to overcome their reading and understanding problems. The interviews from students were conducted at Pakistan in April and May, 2015. There were eight focus group interviews for engineering students; each group consisted of five students. These interviews were recorded using audio tape and transcribed for analysis and results. The data was organized using 
NVivo software version 8 . The researcher analyzed the qualitative data of this research by following Strauss and Corbin (1990) which generated the final themes as given in the results section.

\section{Findings of the Study}

The informants of eight groups came to know about what potential metacognitive strategies were noted as beneficial to develop their comprehension in reading academic as well as general texts and their level of reading growth. Conversely, differences were investigated while using each and every metacognitive strategy among all groups who participated in this study. Similarly, the focus group interview data gathered was analyzed and the main themes generated for the interpretation of the results are presented in table 1 of this study.

Table 1.Presenting main themes of the study

\begin{tabular}{lll}
\hline Level One Code & Level Two Codes \\
\hline Metacognitive Strategies & 1. & Thinking through images of the texts \\
(Planning, Monitoring, \& & 2. & Selecting the Main ideas \\
Evaluating) & 3. & Selecting the topic Sentences \\
& 4. & Scanning of the texts \\
5. & Summarizing of the texts \\
& 6. & Questioning \\
\hline
\end{tabular}

\subsection{Thinking Through Images of the Texts}

The first item of the level-two theme is the thinking through images of the text in which most of the groups reported that thinking and making images of the text is the most important strategy for understanding of the text but they did not use this strategy frequently because using mental image leads thinking about the passages take lot of time. Three of these groups informed that they used this strategy in predicting and linking text with their thoughts and form meaning at the time of difficult text. Most of the groups considered this strategy as the most beneficial to develop reading and comprehension. These groups observed:

"We start reading directly....and we never waste our time in thinking and image making of the text. Sometimes...we used thinking about text when we find difficult text in the article.....but thinking is important...." [Group Two]

“...we find information through guesstimating of the text, then slowly and gradually continue reading......it is very hard for predicting and linking text with our thoughts and forming its meaning through our images of the text. Reading passages by following images in our mind about text is necessary to understand the meaning of the text." [Group One]

"Firstly....students should read text without making imagery of the text. Second...we should not make images by thinking and brainstorming to save our time.... because we cannot interlink text with thoughts in mind..." [Group Three]

Conversely, two of these groups believed that this strategy is very essential to make mental images for titles and subtitles and can form imagery of the material from that of titles before reading. They reported:

"We believe that this strategy [thinking] is very essential to make mental images for the titles and subtitles....so we form imagery of the material in the passage and involve our thoughts and our brainstorms...." [Group Five]

"....the images making through thinking can connect mental links of the text with that of personal thoughts. This strategy can help readers to understand written text... and to develop reading." [Group Six]

Interestingly, two of these groups informed that they often linked texts with that of their mental thoughts to evaluate their understandings of the text. These two groups noted:

"Firstly...reader should find headings and sub headings of the text to apprehend its meaning completely. Secondly....they should go through the world of imagination about the text for better comprehension in depth. Finally...we can interlink our thoughts with our reading to reach exact meaning of the texts..." [Group Seven]

"When we read...we try to imagine about all the key information used and connect our thoughts....and imagination with that of text. We think this strategy [thinking] would help us to understand the text in a better way... and students can perform independently...." [Group Eight] 


\subsection{Selecting the Main Ideas}

The second item of the level-two theme is selecting main ideas of the text. They believed that the main ideas help them to comprehend the important concepts in the text as they read the text. They practice a lot on this activity by finding out the main details of the text. Three of the groups informed that searching the main ideas of a passage seemed very important in reading to enable them to comprehend the key details of the text easily and quickly. This strategy had developed their reading proficiency and had paved a way for them to practice a lot with complete comprehension of the passages. Conversely, three of the groups informed that they do not know how to find and where to find the main idea in the passage of the article. Additionally, they had little practice and knowledge in searching out the key details or main ideas within the text. This strategy seemed very difficult for them to follow. Some of the examples are given here:

“....selecting main ideas are the important strategy for students to understand passages of the article. We should find the main ideas either in the first sentence or in the last sentences of a paragraph in the text....finding main ideas can develop our level of comprehension of the text....." [Group Three]

"To us...this strategy is very essential to follow....so, we depend on reading the text again and again to comprehend it with the help of main ideas and supporting details. Selecting the main ideas can clarify about text and showed the involvement of readers...." [Group Two]

Importantly, three of these groups stated that they did not pay attention to select main ideas in the text. For them, this strategy took a lot of their time in finding out the main ideas. Three of these groups observed:

"We do not pay attention.....to select the main ideas in the text. We think...this strategy took a lot of time in finding out the main ideas. We have little knowledge and very little practice on selecting key ideas...." [Group Four]

"Students should read text slowly and gradually for comprehension purposes.....and they should underline the main ideas to support their level of understanding. We believe the main idea as significant to cognize the article...." [Group Six]

“....yes...selecting the main idea is very important for understanding the text. Weak students do not select the main ideas from the text as they do not know how to find and where to find and what to select....this is because of their little practice on reading...." [Group Five

Most interestingly, one of these groups stated that they believed the main ideas can help them to comprehend the important concepts of the text. If they would read the text a lot, they would practice much to find out the main details of the text. This group noted:

"......while reading...we see the different traits and features of the text...and find the main theme either in the first sentence or in the last sentence. We think...without looking main details is just like wasting of time. This strategy is beneficial for developing comprehension...." [Group Seven]

\subsection{Selecting the Topic Sentences}

The third item of the level-two theme is selecting the topic sentences from the text in which some of the groups reported that they try to read the first sentence of each passage in terms of determining the topic sentences. Moreover, these respondents indicated that their teachers taught them to look at the first sentence of a paragraph because the topic sentence can easily be obtained from the very first sentence of each paragraph. These groups noted:

“...the first sentence in each paragraph has topic sentence....the first sentence tells us the main concept of the article. Students who have lot of reading practice can easily identify... and those who do not practice on reading activities...cannot identify topic sentences and would face difficulties in perception of the meaning of the text...." [Group Two]

“...the topic sentence is important for understanding the context of text...this [topic sentence] guides us to develop our thoughts. We should practice on reading as we should know what the topic sentence is.... and how to select topic sentence from paragraph." [Group Three]

“...whenever, we find topic sentences...we get the main idea of the text that helps us to understand the text properly. So, we read the main sentence with great importance in order to find the meaning of the text...." [Group One] 
"We should search topic sentence before starting our reading. Our teachers have guided us that the topic sentence remains hidden in the first sentence....the topic sentence helps us to understand the text quickly...." [Group Four]

Interestingly, two of these groups informed that they looked for the main sentences in the very first attempt. These groups described:

"We know...the topic sentence is given in beginning of each paragraph of the article. It [the topic sentence] is the most essential sentence within the passage of the article. The topic sentence helps us to know what would lay hidden in the sentence....it [the topic sentence] increases our comprehension and tells us about supporting details...." [Group Eight]

“......while reading a paragraph....we should find the topic sentences.....because the main sentence is very important and it remains hidden in the first sentence. The topic sentence informs us about the complete detail of the text." [Group Seven]

\subsection{Text Scanning}

In this fourth item of level-two, most of the groups informed that scanning is very important strategy for reading and comprehension. These groups reported that soon after scanning text, they start reading to obtain the central ideas of the text. This strategy helped them to increase their interest in reading. These groups commented:

".....we read to know the main aim of a paragraph and what kind of information is discussed in the text....then we scan the text for key information..." [Group Three]

"We used to scan paragraph to evaluate... what does it inform about....and what purpose it would serve? Afterwards, we continue reading passages slowly and gradually to obtain complete meaning of the text. If we do not understand... we do read again and again the written text." [Group One]

"Scanning helps readers to know the main purpose of the article and get the first-hand knowledge of the text....scanning strategy makes students aware of the most important knowledge in the passage. If they fail to get the key information of the text...they continue reading till they understand...." [Group Two]

"...before reading article in detail.....we use scanning strategy to find important words or sentences. One important point is that.......we scan text to find supporting detail and headings or titles within the passages. Hmm...we know that every first sentence of the passage tells clearly about the main titles. So...we focus on the text to find information which we need...." [Group Eight]

\subsection{Summarizing of the Texts}

Text summarizing is the fifth item of level-two in metacognitive strategies. Most of the groups indicated that they summarized the text after completion of reading activity. Three of these groups stated that text summarizing is very beneficial strategy that enables them to practice more independently. These groups said:

"After the end of reading passages....we should summarize the text. We mostly review paragraphs for obtaining enough information.... in terms of difficult sentences and unfamiliar words in the text...." [Group Three]

“....we can summarize the text after reading comprehension tasks complete....as we find difficult terms, problematic sentences, and confused parts of the text. If sometimes... we firstly reread the text three times....then would summarize the passages to develop our knowledge for understanding." [Group One]

“....summarizing is very beneficial strategy. This strategy can enable us to practice more independently on the text. This strategy can help us to groom our reading proficiency...." [Group Two]

"We summarize the main points of the passage. If we do not understand something in the text....we reread to know the exact meaning of the texts...." [Group Seven]

\subsection{Questioning}

Questioning strategy in level-two of metacognitive strategies is the sixth item. Most of the groups reported that they used this strategy to ask questions to develop their reading and to find answers in terms of the texts. These groups stated that they used this strategy at the difficult parts of the texts to enhance their understanding of the text. These groups noted:

“......self-questioning strategy is beneficial....and we should ask different self-questions in beginning, during, and after reading comprehension activity. We also use self-questions to clarify the text when we found the passages with difficult language...." [Group Two] 
"...we ask questions either in the beginning or after the end of my reading to confirm my understandings of the texts. Self-questioning strategy makes my reading very easy to know the meaning of the text..." [Group One]

"....we did not use this strategy [self-questioning]...when the text in reading tasks is simple. We use self-questions at the difficult parts of the texts to make our understanding clear to practice..." [Group Four]

Interestingly, two of these groups reported that this strategy can help them to understand the text easily and draws their attention towards paragraphs. These groups avoided all confused parts of the texts. Two of these groups stated:

“....we should use self-questioning strategy in pre reading, during reading, and after reading. Before starting to read....we should ask various questions about the problems discussed in the text. During reading activity......we should question to confirm our hypotheses. After reading.... we should ask to verify our proficiency level...." [Group Six]

"....self-questioning strategy is important for us to know the answers of the problems in the text. We use questions to analyses our learning progress in classroom activities....." [Group Eight]

\section{Summary and Implications of the Study}

The main aim of this study was to investigate the use of metacognitive strategies by first year engineering students in classroom reading practice. The researchers of the study followed Flavell's $(1979,1987)$ theory of metacognition and in results, theoretical contribution in line of metacognition strategies were contributed to develop comprehension of engineering students in Pakistan. The data of this study generated thinking through images of the texts, selecting the main ideas, selecting the topic sentences, scanning of the texts, summarizing of the texts, and questioning strategy to develop reading proficiency of students and their comprehension performance. The results of the present study indicated that the students used thinking through images of the text and questioning strategies as their planning; applied strategies including selecting the main ideas, selecting the topic sentences, and scanning of the texts as the evaluating; and practiced through summarizing of the texts as their evaluating strategy. The findings of this research have implications both for research and educational practices. Implications for practice include the necessity of developing interventions to help students develop more effective strategies. Therefore, study implications are presented as follows:

1) Engineering students should be provided information of metacognitive strategies as the most effective tools for reading text; further, engineering teachers should be encouraged to scaffold their students to use metacognitive strategies.

2) There is currently limited research in the area of metacognition in terms of engineering education. As critical as metacognition is in the area of problem solving and conceptual learning, it is critical to understand how metacognition can help engineering students learning difficult contents more effectively. While students can learn much from the fields of physics and mathematics education.

To conclude, the findings of this study reported that metacognitive strategies including many among thinking, text scanning, text summarizing, and self-questioning strategy were considered as the most essential for effective comprehension and learning how to read with complete meaning of the texts. In short, this study has provided the substantiations that engineering students can develop their reading comprehension ability through metacognitive strategies.

\section{References}

Alderson, J. C. (2000). Assessing reading. Cambridge: Cambridge University Press. https://doi.org/10.1017/CBO9780511732935

Antonietti, A., Ignazi, S., \& Perego, P. (2000). Metacognitive knowledge about problem-solving methods. British Journal of Educational Psychology, 70(1), 1-16.https://doi.org/10.1348/000709900157921

Ballou, A. K. (2012). Using explicit strategy instruction to improve reading comprehension. Education Masters, Paper 221.

Boulware-Gooden, R., Carreker, S., Thornhill, A., \& Joshi, R. (2007). Instruction of metacognitive strategies enhances reading comprehension and vocabulary achievement of third-grade students. Reading Teacher, 61(1), 70-77. https://doi.org/10.1598/RT.61.1.7

Brown, A. (1987). Metacognition, executive control, self-regulation, and other more mysterious mechanisms. In F. Weinert \& R. Kluwe (Eds.), Metacognition, motivation, and understanding (pp. 65-116), Hillsdale, NJ: Erlbaum. 
Butler, D. L., Cartier, S. C., Schnellert, L., Gagnon, F., \& Giammarino, M. (2011). Secondary students' self-regulated engagement in reading: researching self-regulation as situated in context. Psychological Test and Assessment Modeling, 53(1), 73-105.

Case, J., Gunstone, R., \& Lewis, A. (2001). Students' metacognitive development in an innovative second year chemical engineering course. Research in Science Education, 31(3), 313-335. https://doi.org/10.1023/A:1013113807788

Channa, M. A., \& Nordin, Z. S. (2014). Identifying metacognitive strategies through learners' reading comprehension: a review of related studies. Sci.Int.(Lahore), 26(5), 2457-2460.

Channa, M. A., \& Nordin, Z. S. (2015). Social cognitive theory and the zone of proximal development in the learning of reading comprehension. Sci. Int.(Lahore), 27(1), 581-585.

Channa, M. A., Nordin, Z. S., Siming, I. A., Asgher Chandio, A., \& Koondher, M. A. (2015). Developing reading comprehension through metacognitive strategies: A review of previous studies. English Language Teaching, 8(8), 181-186.

Chi, M. T. H., Bassok, M., Lewis, M. W., Reimann, P., \& Glaser, R. (1989). Self-Explanations: how students study and use examples in learning to solve problems. Cognitive Science, 13(2), 145-182. https://doi.org/10.1207/s15516709 $\operatorname{cog} 1302 \_1$

Cohen, A. D. (1998). Strategies in learning and using a second language. NY: Addison Wesley Longman.

Demetriou, A. (2000). Organization and development of self-understanding \& self- regulation: towards a general theory. In M.Boekaerts, P. R. Pintrich, \& M. Zeidner (Eds.), Handbook of Self-Regulation. London Academic Press. https://doi.org/10.1016/B978-012109890-2/50036-6

Flavell J. H. (2004). Theory-of-mind development: Retrospect and prospect. Merrill-Palmer Quarterly, 50, 274-290. https://doi.org/10.1353/mpq.2004.0018

Flavell, J. H. (1979). Metacognition and cognitive monitoring: A new area of cognitive-developmental inquiry. American Psychologist, 34(10), 906-911. https://doi.org/10.1037/0003-066X.34.10.906

Flavell, J. H. (1987). Speculations about the nature and development of metacognition, In F. E. Weinert \& R. H. Kluwe (Eds.), Metacognition, motivation and understanding (pp. 21-29), London: Lawrence Erlbaum Associates, Inc.

Fleming, F., \& Walls, G. (1998). What pupils do: The role of strategic planning in modern foreign language learning? The Language Learning Journal, 18(1), 14-21. https://doi.org/10.1080/09571739885200201

Franco-Castillo I. (2013). The relationship between scaffolding metacognitive strategies identified throughdialogue journals and second graders' reading comprehension, science achievement, and metacognition using expository text. FIU, Electronic Theses and Dissertations, Paper 1014.

Grotzer, T., \& Mittlefehldt, S. (2012). The role of metacognition in students' understanding and transfer of explanatory structures in science. In A. Zohar \& Y. J. Dori (Eds.), Metacognition in Science Education: Trends in Current Research.Springer. https://doi.org/10.1007/978-94-007-2132-6_5

Hammadou, J. (1991). Interrelationship among prior knowledge, inference, and language proficiency in foreign language reading. The Modern Language Journal, 75(1), 27-38. https://doi.org/10.1111/j.1540-4781.1991.tb01080.x

Huff, J. D., \& Nietfeld, J. L. (2009). Using strategy instruction and confidence judgments to improve metacognitive monitoring. Metacognition and Learning, 4(2), 161-176.https://doi.org/10.1007/s11409-009-9042-8

James, I. (2010). The use of metacognitive scaffolding to improve college students' academic success. Journal of College Teaching \& Learning, 7, 47-50. https://doi.org/10.19030/tlc.v7i11.251

Joesba, M., \& Ardeo, G. (2005). Student engineers, ESP courses, and testing with cloze tests. ESP World, 2(10). Retrieved from http://www.esp-world.info/contents.htm

Keene, E. O., \& Zimmerman, S. (1997). Mosaic of thought: Teaching comprehension in a reader's workshop. Portsmouth, NH: Heinemann.

King, P. M., \& Kitchener, K. S. (2004). Reflective Judgment: Theory and research on the development of epistemic assumptions through adulthood. Educational Psychologist, 39(1), 5-18. https://doi.org/10.1207/s15326985ep3901_2 
Koch, A. (2001). Training in metacognition and comprehension of physics texts. Science Education, 85, 758-768.https://doi.org/10.1002/sce.1037

Koutselini, M., \& Theofilides, C. (2001). Inquiry and Cooperation. Athens: Grigoris Press.

Kramarski, B., \& Mevarech, Z. R. (2003). Enhancing mathematical reasoning in the classroom: The effects of cooperative learning and metacognitive training. American Educational Research Journal, 40(1), 281-310.https://doi.org/10.3102/00028312040001281

Liao, H. C., \& Chen, Y. H. (2012). English-for-science-and technology teaching materials: Phase one evaluation. English Language Teaching, 5(6), 89-94. https://doi.org/10.5539/elt.v5n6p89

Litzinger, T. A., Meter, P. V., Firetto, C. M., Passmore, L. J., Masters, C. B., Turns, S. R., \& Zappe, S. E. (2010). A Cognitive Study of Problem Solving in Statics. Journal of Engineering Education, 99(4), 337-353. https://doi.org/10.1002/j.2168-9830.2010.tb01067.x

Maki, R. H., \& McGuire, M. J. (2002). Metacognition for text: Findings and implications for education. In T. J. Perfect \& B. L. Schwartz (Eds.), Applied metacognition (pp. 39-67). New York: Cambridge University Press. https://doi.org/10.1017/CBO9780511489976.004

Mevarech, Z. R., \& Amrany, C. (2008). Immediate and delayed effects of metacognitive instruction on regulation of cognition and mathematics achievement, Metacognition Learning, 3(2), 147-157.https://doi.org/10.1007/s11409-008-9023-3

Mudray, O. (2006). Engineering English: A lexical frequency instructional model. English for Specific Purposes, 25(2), 235-256. https://doi.org/10.1016/j.esp.2005.05.002

Oxford, R. (1990). Language learning strategies: What every teacher should know. New York: Newbury House.

Palinscar, A., \& Brown, A. (1984). Reciprocal teaching of comprehension-fostering and comprehension monitoring activities. Cognition and Instruction, I(2), 117-175. https://doi.org/10.1207/s1532690xci0102_1

Pritchard, R. M. O., \& Nasr, A. (2004). Improving reading performance among Egyptian engineering students: Principles and practice. English for Specific Purposes, 23, 425-445. https://doi.org/10.1016/j.esp.2004.01.002

Salataci, R., \& Akyel, A. (2002). Strategy training in L1 and L2 reading. Reading in a Foreign Language, 14(1), $1-17$.

Schwartz, B. L., \& Perfect, T. J. (2002). Introduction: Toward an applied metacognition. In T. J. Perfect \& B. L. Schwartz (Eds.), Applied metacognition (pp. 1-11), New York: Cambridge University Press.https://doi.org/10.1017/CBO9780511489976.002

Shah, P. M., Yusof, A., Lip, S. M., Mahmood, N., Hamid, Y. E. A., \& Hashim, S. M. (2010). Comparing reading processing strategies of second language readers. Am. J. Applied Sci., 7, 140-144. https://doi.org/10.3844/ajassp.2010.140.144

Shiotsu, T., \& Weir, C. J. (2007). The relative significance of syntactic knowledge and vocabulary breadth in the prediction of reading comprehension test performance. Language Testing, 24, 99-128. https://doi.org/10.1177/0265532207071513

Sinthopruangchai, S. (2011). A study of Thai EFL learners' metacognition awareness of reading strategies (Master Research Paper Unpublished). Language Institute, Thammasat University, Bangkok, Thailand.

Song, M. (1998). Teaching reading strategies in an ongoing EFL university reading classroom. Asian Journal of English Language Teaching, 8, 41-54.

Steif, P. S., Lobue, J. M., Kara, L. B., \& Fay, A. L. (2010). Improving problem solving performance by inducing talk about salient problem features. Journal of Engineering Education, 99(2), 135-142. https://doi.org/10.1002/j.2168-9830.2010.tb01050.x

Strauss, A., \& Corbin, J. (1990). Basics of qualitative research. California: Sage Publications.

Streveler, R. A., Litzinger, T. A., Miller, R. L., \& Steif, P. S. (2008). Learning conceptual knowledge in the engineering sciences: Overview and future research directions. Journal of Engineering Education, 97(3), 279-294. https://doi.org/10.1002/j.2168-9830.2008.tb00979.x

Tarricone, P. (2011). The taxonomy of metacognition. Hove, UK: Psychology Press. 
Venkatraman, G., \& Premak, P. (2007). English language skills for engineering students: A need survey. ESP World, 3(16).

Ward, J. (2009). A basic engineering English word list for less proficient foundation engineering undergraduates. English for Specific Purposes, 28, 170-182. https://doi.org/10.1016/j.esp.2009.04.001

Wei, Y. (2005). The relationship between phonological awareness and reading ability of Thai students in English and Thai primary schools of Thailand. Curriculum and Instruction, Theses and Dissertations, UM Theses and Dissertations (UMI No. 3175161), ProQuest Information and Learning: Collage Park, MD.

White, B. Y., \& Frederiksen, J. R. (1998). Inquiry, modeling, and metacognition: Making science accessible to all students. Cognition and Instruction, 16(1), 3-118. https://doi.org/10.1207/s1532690xci1601_2

White, C. J. (1995). Autonomy and Strategy Use in Distance Foreign Language Learning: Research Findings. System, 23(2), 207-221. https://doi.org/10.1016/0346-251X(95)00009-9

Young, A., \& Fry, J. D. (2008). Metacognitive awareness and academic achievement in college students. Journal of the Scholarship of Teaching and Learning, 8(2), 1-10.

Zelazo, P. D. (2004). The development of conscious control in childhood, Trends in Cognitive Sciences, 8(1), 12-17. https://doi.org/10.1016/j.tics.2003.11.001

Zimmerman, B. J., \& Schunk, D. H. (2011). Handbook of self-regulation of learning and performance. New York: Rutledge.

\section{Copyrights}

Copyright for this article is retained by the author, with first publication rights granted to the journal.

This is an open-access article distributed under the terms and conditions of the Creative Commons Attribution license (http://creativecommons.org/licenses/by/4.0/). 